\title{
Article
}

\section{Static Behavior of a Retractable Suspen-Dome Structure}

\author{
Xuhong Shen ${ }^{1,2}$, Qian Zhang ${ }^{1}\left(\mathbb{C}\right.$, Daniel Sang-Hoon Lee ${ }^{3}\left(\mathbb{D}\right.$, Jianguo Cai ${ }^{1, *}$ and Jian Feng ${ }^{1}$ \\ 1 National Prestress Engineering Research Center, Key Laboratory of C \& PC Structures of Ministry of \\ Education Southeast University, Nanjing 210096, China; 230188212@seu.edu.cn (X.S.); \\ z.qian@seu.edu.cn (Q.Z.); fengjian@seu.edu.cn (J.F.) \\ 2 China Design Group Co., Ltd., Nanjing 210001, China \\ 3 The Royal Danish Academy, Schools of Architecture, Design and Conservation, 1435 Copenhagen, Denmark; \\ Daniel.Lee@kglakademi.dk \\ * Correspondence: j.cai@seu.edu.cn
}

Citation: Shen, X.; Zhang, Q.; Lee, D.S.-H.; Cai, J.; Feng, J. Static Behavior of a Retractable Suspen-Dome Structure. Symmetry 2021, 13, 1105. https://doi.org/ $10.3390 /$ sym 13071105

Academic Editor: Alexey Lukoyanov

Received: 23 May 2021

Accepted: 16 June 2021

Published: 22 June 2021

Publisher's Note: MDPI stays neutral with regard to jurisdictional claims in published maps and institutional affiliations.

Copyright: (C) 2021 by the authors. Licensee MDPI, Basel, Switzerland. This article is an open access article distributed under the terms and conditions of the Creative Commons Attribution (CC BY) license (https:/ / creativecommons.org/licenses/by/ $4.0 /)$.

\begin{abstract}
A new design of a radially retractable roof structure based on the concept of the suspendome is proposed in this paper. The radially foldable bar structure is strengthened by the lower cable-strut system to obtain a higher structural stiffness. Then the comparison of the static behavior between the retractable suspen-domes and their corresponding foldable bar shell with quadrangular mesh is discussed. Moreover, the effects of different structural and geometric parameters, such as the rise-to-span ratio, the cross-section area of beams, cables and struts, and the pre-stress level of the lower cable-strut system, on the nodal displacements and member forces are investigated systematically. The results show that higher structural stiffness is anticipated with the introduction of cable-strut systems into the hybrid structure. When the rise-to-span ratio is equal to 0.2 , the maximal nodal displacement of the suspen-dome reaches the minimal value. The increase of the cross-section area of steel beams contributes an enormous amount to the structural stiffness. Increasing cable and strut sections has little impact on the mechanical behavior of suspen-domes. Moreover, the prestress level of cable-strut systems has a slight influence on the nodal displacements and member forces. Parametric analysis can be regarded as an essential basis for the optimization of the design of a retractable suspen-dome structure.
\end{abstract}

Keywords: suspen-dome; retractable roof; foldable bar structure; prestress; static behavior

\section{Introduction}

The structural behaviors of single-layer domes are continually investigated [1-4], and stability remains amongst the challenges faced for longer spans [5]. The use of a multiple layer steel-truss for increase flexural stiffness has been investigated [6,7], while the doublelayer systems with greater stability have been discussed as an obvious alternative, yet with additional challenges in some cases. For example, the heavy weight of the dome causes considerable tension in the outer ring girder. The merits of cable domes with tensegrity systems have been demonstrated in past construction (with reference to the stadium in Korea). However, the inherent structural flexibility makes the introduction of large prestresses for the required stability inevitable. The large prestresses must be sustained by the non-cable structural elements, such as outer ring girders, which consequently are to be subjected to large compressive stresses, thus must consume large resources for the construction. The suspen-dome system was developed by Tatemichi et al. [8] and Kawaguchi et al. [9] with the aim to achieve the demanded stability in single-layer domes while reducing the burden on the other supporting structures [10,11]. Moreover, the static and dynamic analysis of the suspen-dome has been conducted by many researchers [12-16].

Retractable roofs are structural systems different in nature to those previously discussed, which involve applied mechanical systems, and are adopted in buildings for multi-functional sports and culture facilities $[17,18]$. The systems enable the users of recreational facilities to enjoy the open-air by temporarily removing the physical boundary of 
the roof. Different types of retractable systems exist, from simple sliding roofs to those structures with multiple deployable degrees of freedom [19]. Retractable roofs eventually become permanent structures at a fixed location [20], and based on certain constraints the system becomes capable of transforming between two to multiple configurations, within the closed and open limit configurations. Among the different types of systems [21,22], those using angulated scissor-like elements (proposed by Hoberman [23]) have drawn the interest of many practitioners, designers, and researchers. These basic units consist of a pair of identical angulated rods connected by a revolute joint and subtending a constant angle as their rods rotate while maintaining the end pivots on parallel lines [24,25]. Based on the closed-loop Hoberman's linkage, You and Pellegrino [26] extended the concept by including additional pairs of bars connected to one another by scissor hinges. The system does not require all the members to be collinear and any number of pairs of bars connected by scissor hinges will maintain its mobility. Thus, the foldable structure, as shown in Figure 1, can be made from multi-angulated rods similar to these angulated, scissor-like elements.
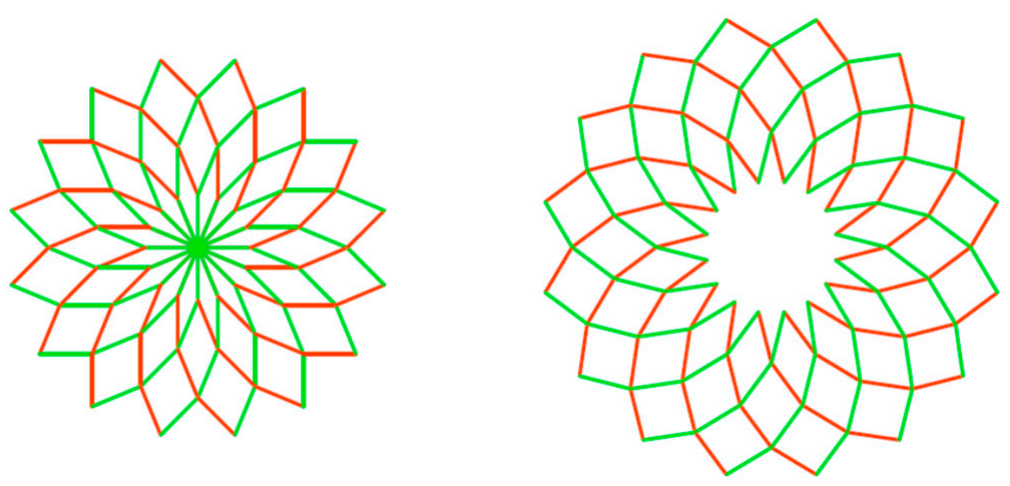

Figure 1. Foldable bar structures.

Teall [27] discussed low stiffness, and thus, deformations of the foldable bar structure under self-weight, even for the three-layer foldable bar structure with a span of just $2 \mathrm{~m}$. Mao and Luo [19] and Cai et al. [28-31] also pointed out that the foldable bar structure is not readily suitable as a retractable roof system unless the structural stiffness can be increased. Therefore, the current investigation was developed to advance the foldable bar structure for its possible application in long-span retractable roofs by adopting the merit of increased stability from suspen-dome systems; a structure which can be eventually referred to as retractable suspen-dome. The lower cable-strut system strengthens the radially upper foldable bar structure to obtain a higher structural stiffness. Besides, the overall displacements and internal deformation should be controlled in the design for the moving requirements.

In this paper, the core aspects for the development of a retractable suspen-dome are presented. Firstly, the overview of the structural system is described in Section 2, which is followed by a comparison of the static behavior between the retractable suspen-dome and the corresponding foldable bar structure in Section 3. A parametric study of the static behavior in respect of geometrical and structural parameters is discussed in Section 4.

\section{Structural System}

The suspen-dome consists of two systems, and the general layout can be described as: (1) the single-layer dome truss on top of the supporting (2) cable-strut structures. For the current research, the upper dome truss is replaced by the foldable bar system, as depicted in Figure 2. In planning, the vertical struts are positioned at the same locations as the revolute connections of the foldable bar structures on top. Thus, during the retraction process, the system simply follows the movement of the foldable bar structure (Figure 3), and the radial cables of the cable-strut system become slack while the lengths of hoop cables increase. 
In the reverse process, the hoop cables are restored back to their initial lengths, as are the radial cables in a passive manner. When the structure is totally closed, the active cables continue to be tensioned, and the lower cable-strut system will have prestresses. In respect of sustaining the load, during most of the retraction and reverse process, as well as at the fully open configuration, the foldable bar structure at the top is the active system. In the closed configuration, both systems are active. Figure 4 gives the diagram of the classical elements of the retractable suspen-dome, and the mock-up model is shown in Figure 5.
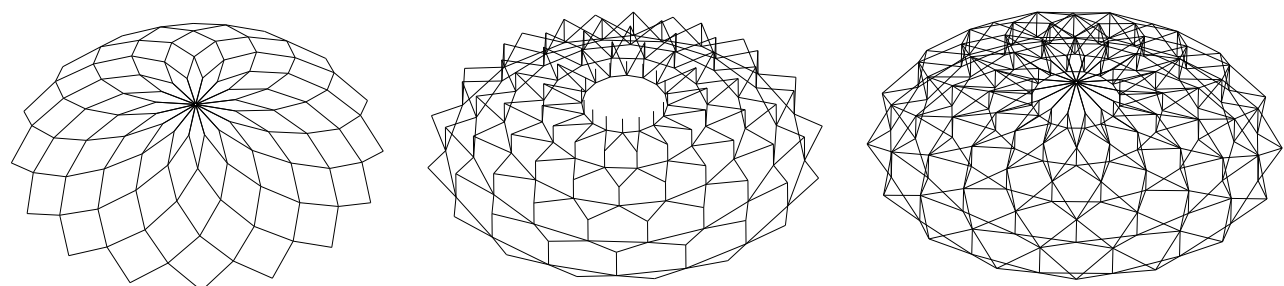

Radially foldable bar system + cable-strut system = retractable suspen-dome

Figure 2. Concept of the retractable suspen-dome.

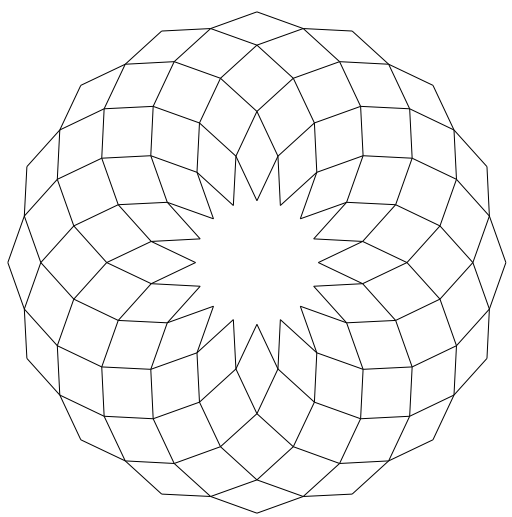

(a) Radially foldable bar system

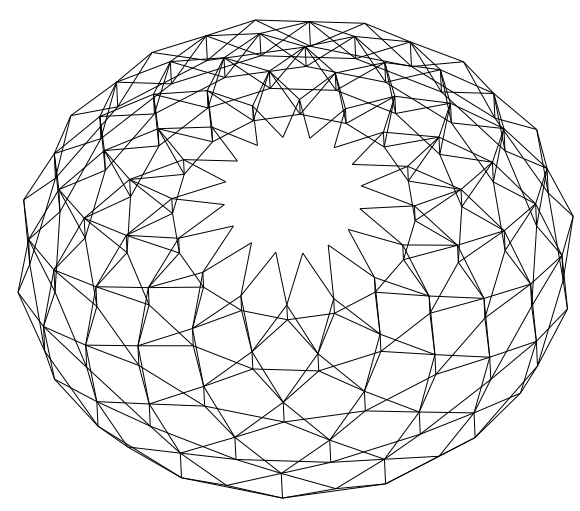

(b) Radially retractable suspen-dome

Figure 3. Radially retractable system during the motion.

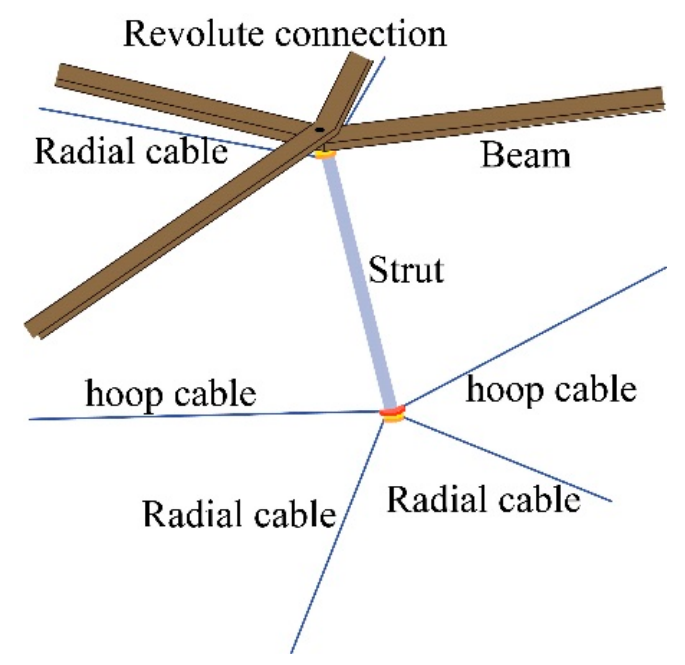

Figure 4. The classical element of the system. 


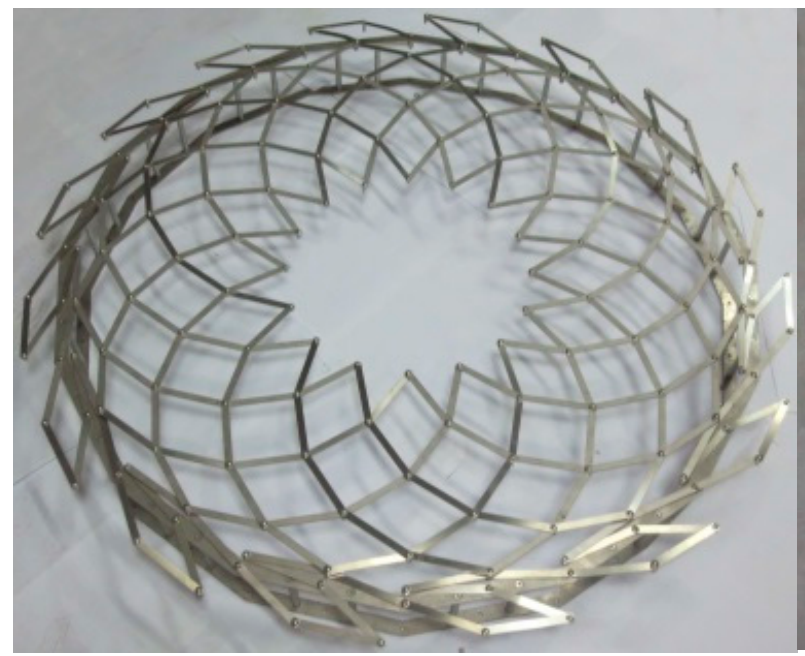

(a) Open configuration

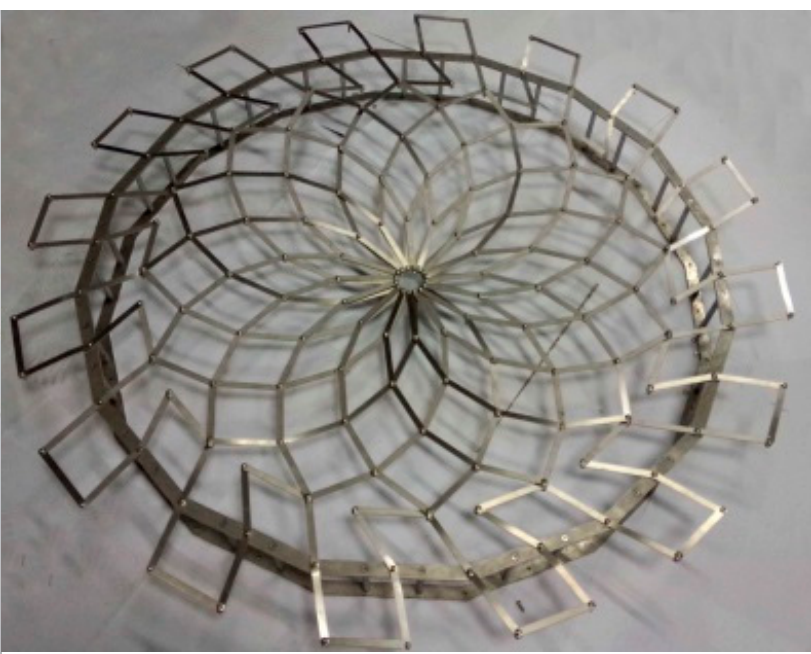

(b) Closed configuration

Figure 5. The mock-up model of the system.

\section{Structural Behavior}

\subsection{Finite Element Model}

A computational model was constructed for the numerical study of a retractable suspen-dome design, as shown in Figure 6. The foldable bar structure has angulated beams with six segments with a constant inclined angle of $157.5^{\circ}$ between each segment. The span is $38 \mathrm{~m}$ with a rise-to-span ratio of 0.2 (Figure 7).

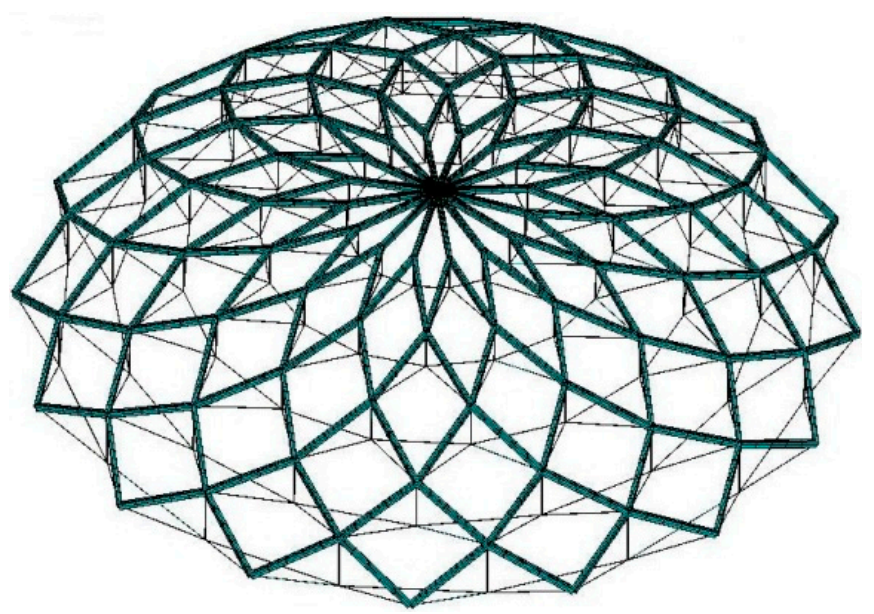

Figure 6. 3D retractable suspen-dome in the closed configuration.

Two load cases are considered in the study: (1) the symmetrical load case of $\mathrm{g}+\mathrm{s}$ (dead load + snow load); and (2) the asymmetrical load case g $+\mathrm{s} / 2$ (s/2 representing snow load distributed over half of the span). The dead load consists of the self-weight of all the beams and cables as $0.5 \mathrm{kN} / \mathrm{m}^{2}$. The snow load is applied in the vertical direction with a magnitude of $0.5 \mathrm{kN} / \mathrm{m}^{2}$.

The finite element software ANSYS 18.0 is utilized for the computation. The BEAM188 element is used to simulate the angulated beams with geometrical nonlinearity considered. The pinned condition was assigned at the joints between the angulated rods, and the fixed boundary condition was assigned on the circumference of the dome. The angulated beams have a Q345B box section in steel, $(300 \times 200 \times 10 \mathrm{~mm})$ and the cables are modelled with a tension-only bar element LINK10, with a corresponding cross-section area of $78.5 \mathrm{~mm}^{2}$. 
The cross-section area of struts, modelled with LINK8, is $706.5 \mathrm{~mm}^{2}$. The Young's modulus of the steel beams, struts, and cables are 210,210 , and $180 \mathrm{MPa}$, respectively.

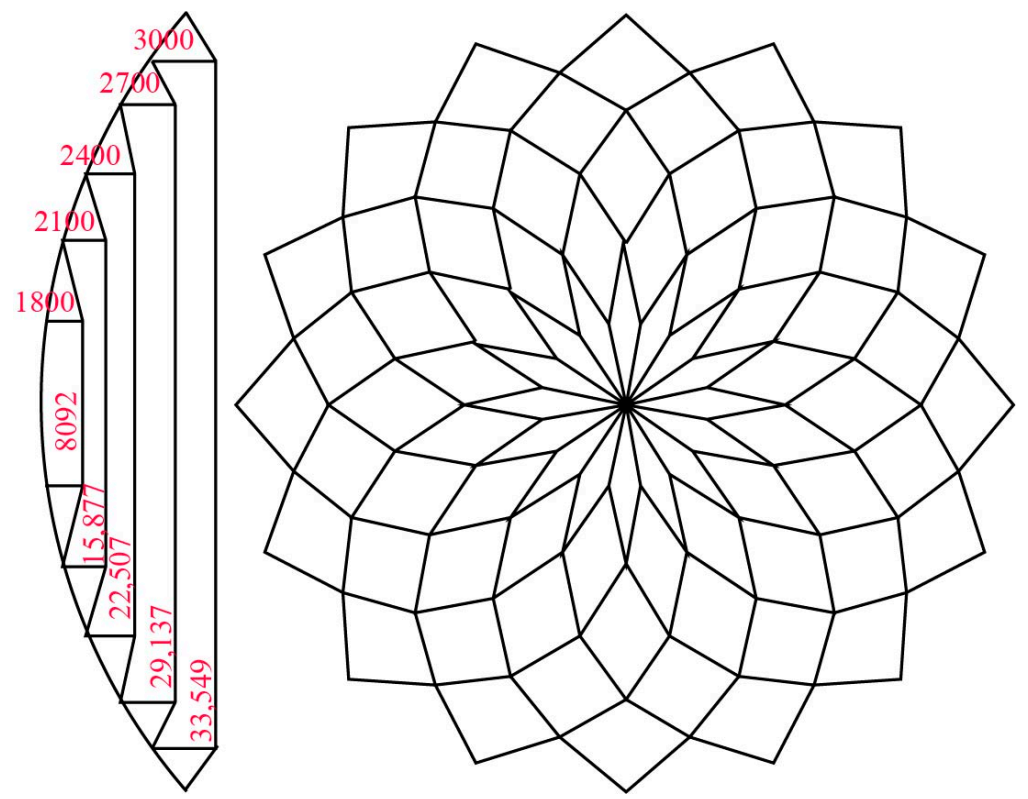

Figure 7. Geometric details of the retractable suspen-dome ( $\mathrm{mm})$.

\subsection{Discussion on the Initial Prestress Level in the Cable-Strut System}

The cable-strut system requires sufficient prestresses for sustaining a vertical position under external loads. The suspen-dome system is very rigid [10], and the nonlinear deformation is minimal even under a large external load. Therefore, the linear behavior of the structure is assumed, and the principle of superposition is applied during the calculation of prestressing levels in the elements.

For the cable-strut structure, which supports the foldable bar structure on top, the number of independent inextensional mechanisms is five, and the number of independent states of self-stress is also five, equaling the number of rings that the structure is consisted of. The equilibrium condition at the nodes, where the three types of elements, radial cables, hoop cables, and vertical struts can be found, is as follows (Figure 8).

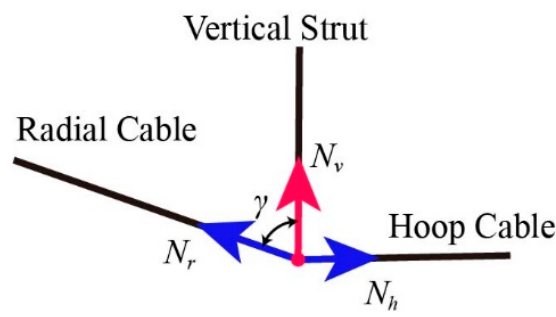

(a) Vertical projection

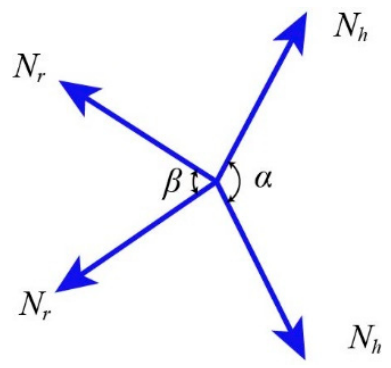

(b) Horizontal projection

Figure 8. Equilibrium of a node of the cable-strut structure in the retractable suspen-dome.

- The relation between the hoop cable forces $N_{\mathrm{h}}$ and the radial cable forces $N_{\mathrm{r}}$ can be expressed as

$$
N_{\mathrm{r}} \sin \gamma \cos \frac{\beta}{2}=N_{\mathrm{h}} \cos \frac{\alpha}{2}
$$


where $\alpha, \beta$ and $\gamma$ represent the angles of adjacent hoop cables, the angle of the horizontal projection of adjacent radial cables, and the angle of radial cable to the vertical axis, respectively.

- We can also obtain the relationship of internal forces of vertical struts $N_{\mathrm{V}}$ and radial cables $N_{\mathrm{r}}$.

$$
N_{v}=2 N_{r} \cos \gamma
$$

Thus the self-stress of each ring in the lower cable-strut structure can be calculated directly. Moreover, the structure can be decomposed of five independent sub-structures, and the corresponding combination coefficients can be determined by the optimization theory. Firstly, the vertical nodal displacement of all nodes of the single-layer dome with dead load can be assembled in the vector $\mathbf{d}_{s l}$. Then, the corresponding nodal displacement related to the state of self-stress of the lower cable-strut system can be regarded as $d i$ $(i=1, \ldots, \mathrm{s})$. Lastly, the nodal displacements of all nodes of the single-layer dome can be expressed with the combination coefficien is $\alpha_{i}(i=1, \ldots, s)$,

$$
\mathbf{d}=\sum_{i=1}^{s} \alpha_{i} d_{i}+\mathbf{d}_{s l}=\left[\begin{array}{llll}
d_{1} & d_{2} & \cdots & d_{s}
\end{array}\right]\left\{\begin{array}{c}
\alpha_{1} \\
\alpha_{2} \\
\vdots \\
\alpha_{s}
\end{array}\right\}+\mathbf{d}_{s l}
$$

And the objective function of the optimization is given by

$$
\min . \quad \psi\left(\alpha_{i}\right)=\|\mathbf{d}\|, i=1 \sim s
$$

We can obtain the initial prestress in the hoop cables from the inner ring to the outer ring as $3.25,15.67,38.47,68.08$, and $100 \mathrm{MPa}$, respectively.

\subsection{Influence of Cable-Strut System on the Static Behavior of Retractable Suspen-Domes}

The aim of the current static analysis is to investigate the stability of the retractable suspen-dome (Figure 9) with respect to external loads. Due to the nature of the structure, the analysis is carried out sequentially in accordance with the construction stages: (1) zero state; 2) initial state; and (3) load state. Zero state is the state of the structure bearing self-weight only prior to any installations. The initial state refers to the state after the necessary finishes, including the installations and applied prestresses. The load state describes any conditions beyond the initial state when any additional live loads, including wind and snow loads, are considered. From the final results of the load state analysis, the corresponding results from the first two states were subtracted to examine the structural behaviour on the effect of the external loads only.

Thus, the current study of static behavior on the structure is based on the results obtained from the following steps:

1. Calculate the nodal displacement and element forces under the zero state;

2. Calculate the nodal displacement and element forces under the initial state;

3. Calculate the nodal displacement and element forces under the load state;

4. Subtract results of the first two steps to obtain the structure response only under external loads (without considering self-weight and prestresses).

For the investigation, the nodal displacements and axial forces in the steel beams of the retractable suspen-domes are compared with the single-layer foldable bar structure without any supporting cable-strut system. Both cases of symmetric (Load 1) and asymmetric (Load 2) loads were considered, and the results are shown in Figures 10 and 11. The deflections in the structure with the cable-strut system are reduced in comparison with the case of only the foldable bar structure. Especially near the mid-span, the maximum 
deflection in the suspen-dome with the cable-strut structure is only about $27 \%$ and $20 \%$ of the foldable bar structure only under Load 1 and Load 2, respectively.

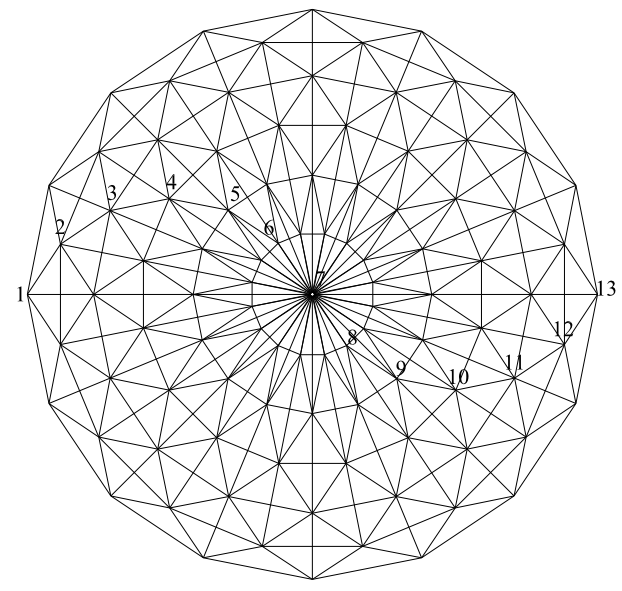

(a) Nodes

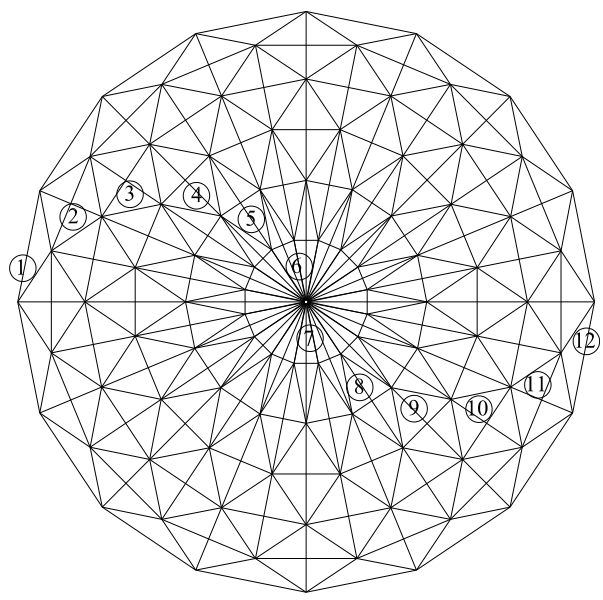

(b) Elements

Figure 9. Typical nodes and elements.

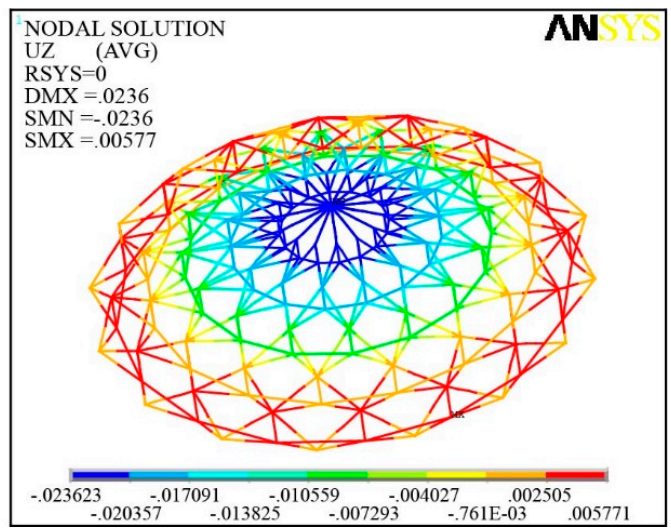

(a) Load 1

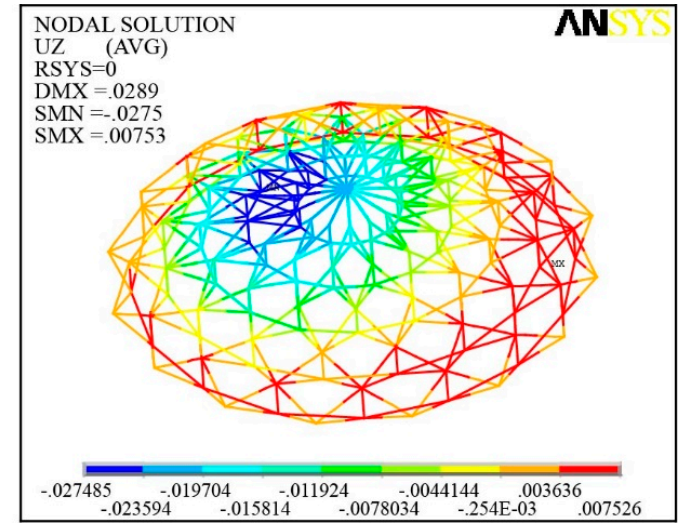

(b) Load 2

Figure 10. Displacement distributions of the retractable suspen-dome structure.

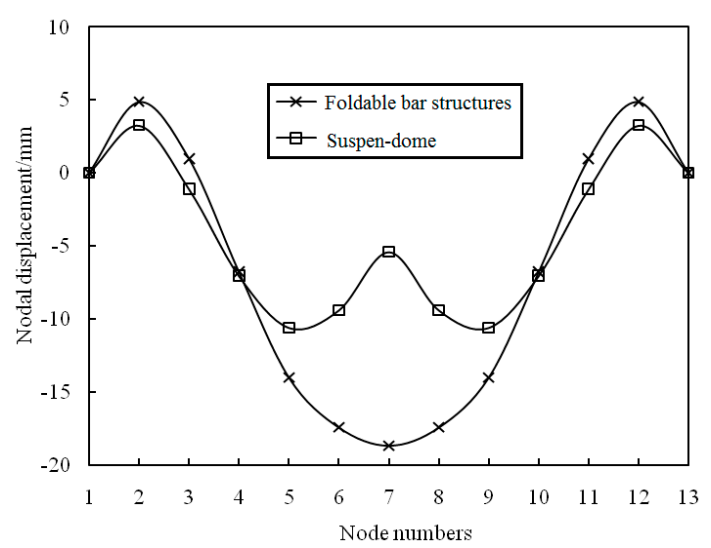

(a) Load 1

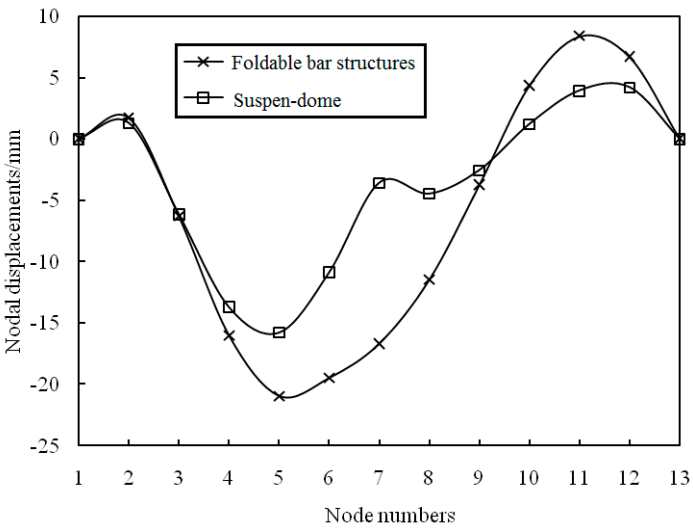

(b) Load 2

Figure 11. Nodal displacements of the suspen-domes and corresponding foldable bar structures. 
Figure 12 shows the comparison of the axial stresses. It can be found that the axial stresses in the steel bars are slightly lower in the suspen-dome, and the differences are more notable near the mid-span again in the case of Load 2.

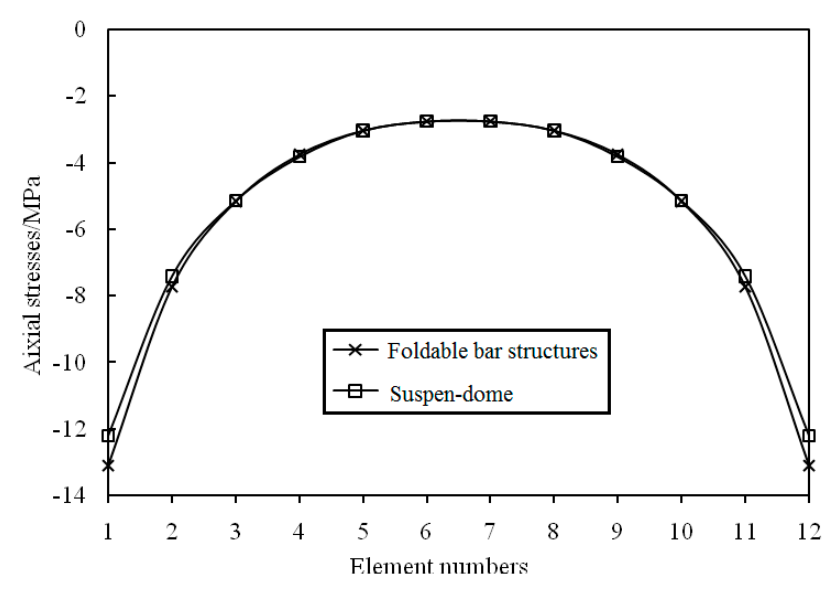

(a) Load 1

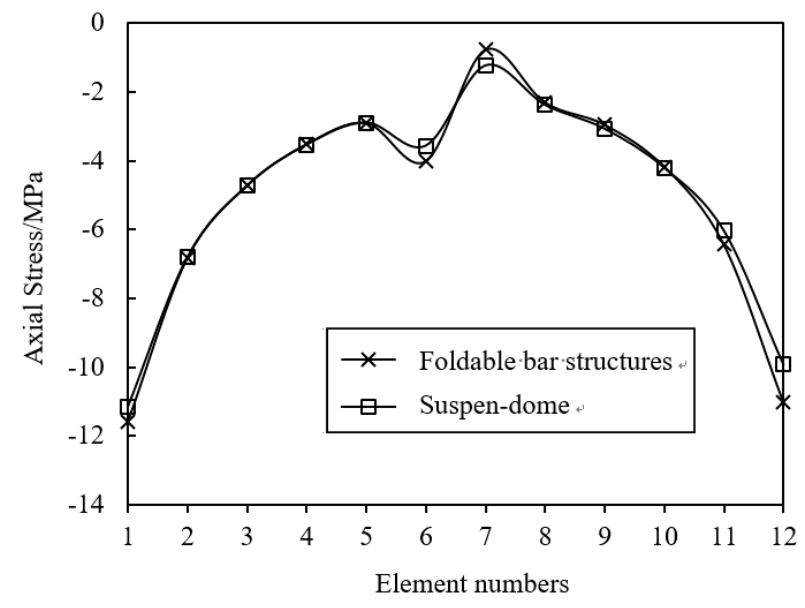

(b) Load 2

Figure 12. Axial stress of the suspen-domes and corresponding foldable bar structures.

\section{Parametric Analysis for the Retractable Suspen-Dome}

\subsection{Influence of the Rise-to-Span Ratio}

The rise-to-span ratio profoundly influences the behavior of single-layer lattice shell structures. The nodal vertical displacements of structures with the four modified rise-tospan ratios of 0.10, 0.15, 0.20, and 0.25 are given in Figure 13. For Load 1, the vertical nodal displacement at the mid-span of the system decreases with the increase of the rise-to-span ratio. For Load 1, the maximal nodal displacement does not occur at the mid-span, and the value is the least when the rise-to-span ratio is 0.2 , which is thus considered optimal. For Load 2, the displacements under the snow load again decrease when the rise-to-span ratio increases. While on the other half-span, the nodal displacements are lower and mostly increase with the rise-to-span ratio, except in the case of 0.1 (Figure 13b).

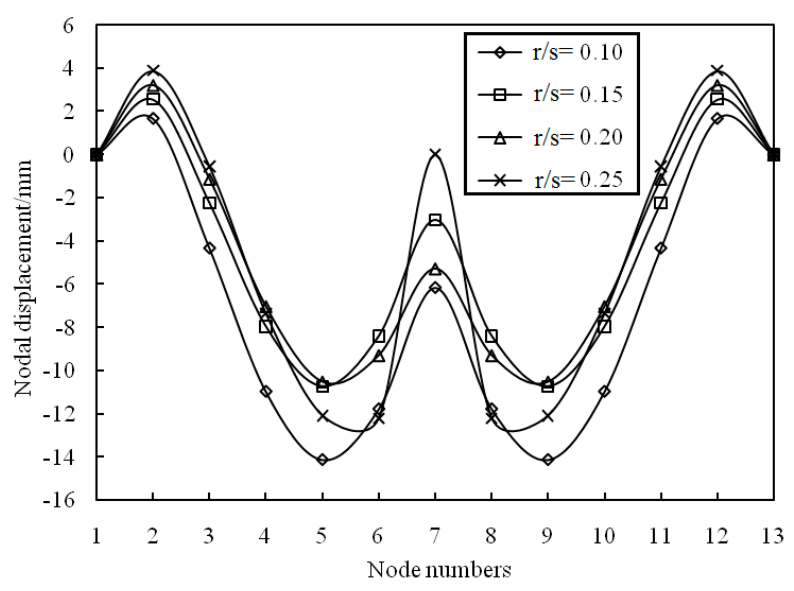

(a) Load 1

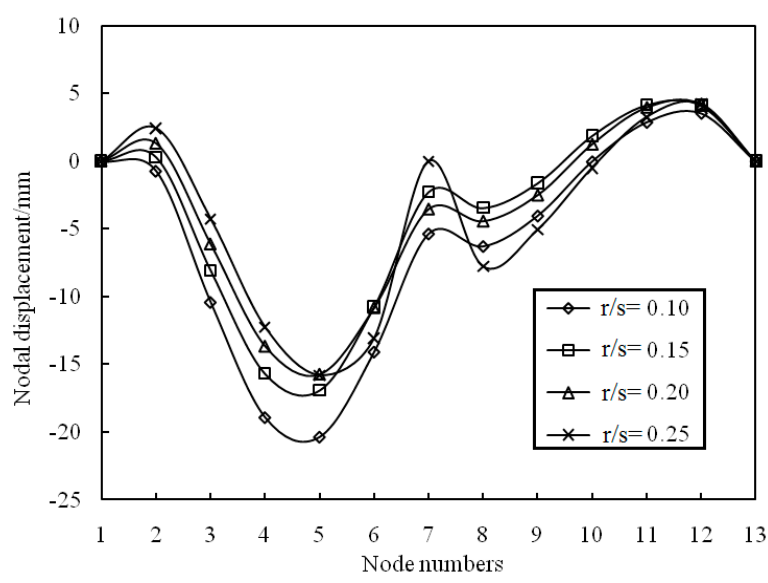

(b) Load 2

Figure 13. Influence of the rise-to-span ratio on nodal displacements.

The variation of axial stress on steel beams with different rise-to-span ratios is shown in Figure 14. The general overview is that the rise-to-span ratio has a significant influence on the axial forces of the beams of the foldable bar structure, and the relationship is 
straightforward. Under both the symmetric and asymmetric load cases, the axial stresses decrease with the increase of rise-to-span ratios.

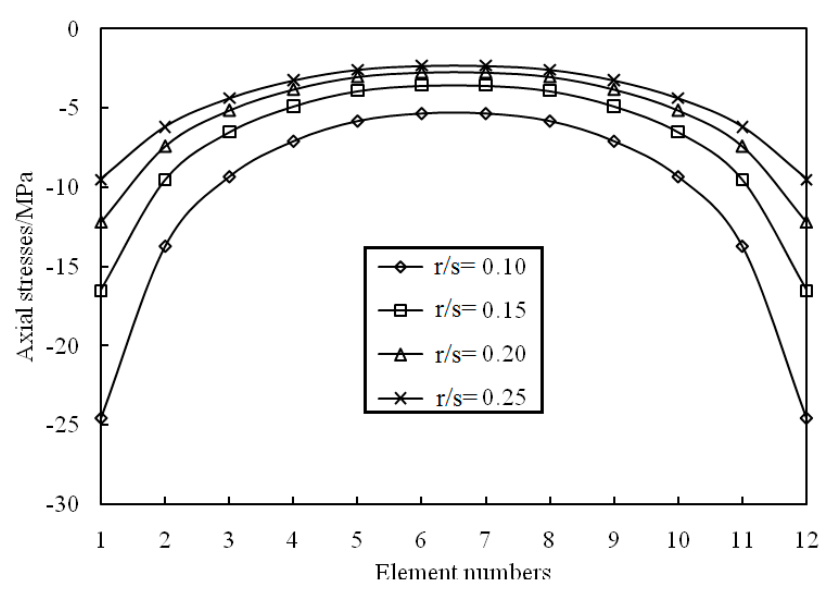

(a) Load 1

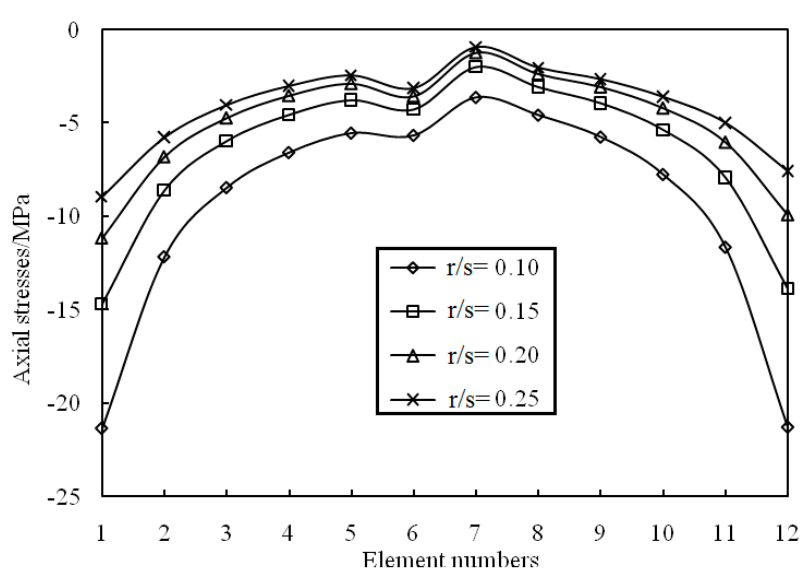

(b) Load 2

Figure 14. Influence of rise-to-span ratios on beam stresses.

\subsection{Influence of the Cross-Section Area of Steel Beams}

Different cross-section areas of steel beams $(250 \times 150 \times 10 \mathrm{~mm}, 300 \times 200 \times 10 \mathrm{~mm}$, $350 \times 200 \times 10 \mathrm{~mm}, 400 \times 200 \times 10 \mathrm{~mm}$, and $450 \times 200 \times 10 \mathrm{~mm}$ ) are chosen for the static analysis of the retractable suspen-dome. The vertical nodal displacements with different cross-section areas of steel beams are shown in Figure 15, and the vertical stiffness of the structure has been improved by the increase of the cross-section areas of the steel beams. Consequently, the vertical nodal displacements decrease. However, the impact of the cross-section areas gradually reduce on the vertical displacements of the structure.

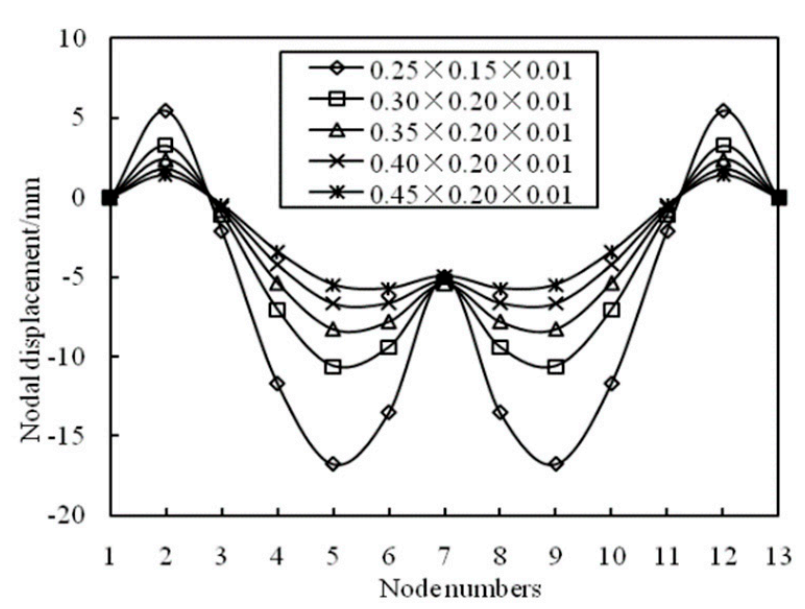

(a) Load 1

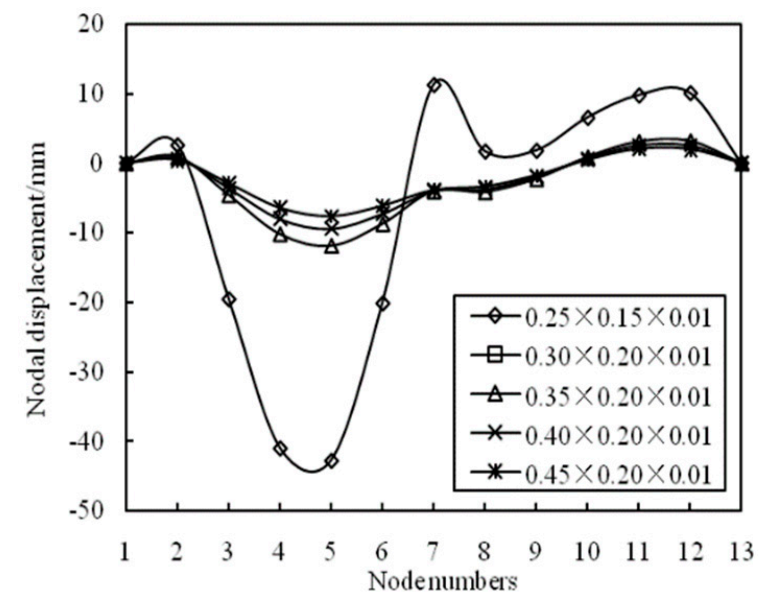

(b) Load 2

Figure 15. Influence of cross-section areas of steel beams on nodal displacements.

Figure 16 shows the plots of axial stresses in the steel beams with different crosssection areas. It can be observed that the axial stress of beams decreases when cross-section areas are increased. The influence on static behaviors of the structure is notable. However, if the stiffness of the foldable structure becomes overly dominant, it will impede the response of the lower cable-strut system. Thus, the overall structural behavior becomes inefficient. 


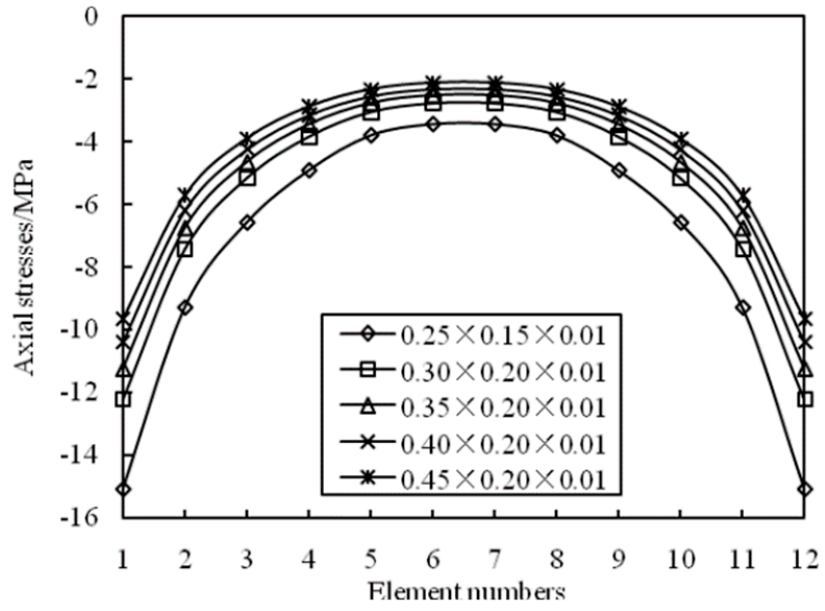

(a) Load 1

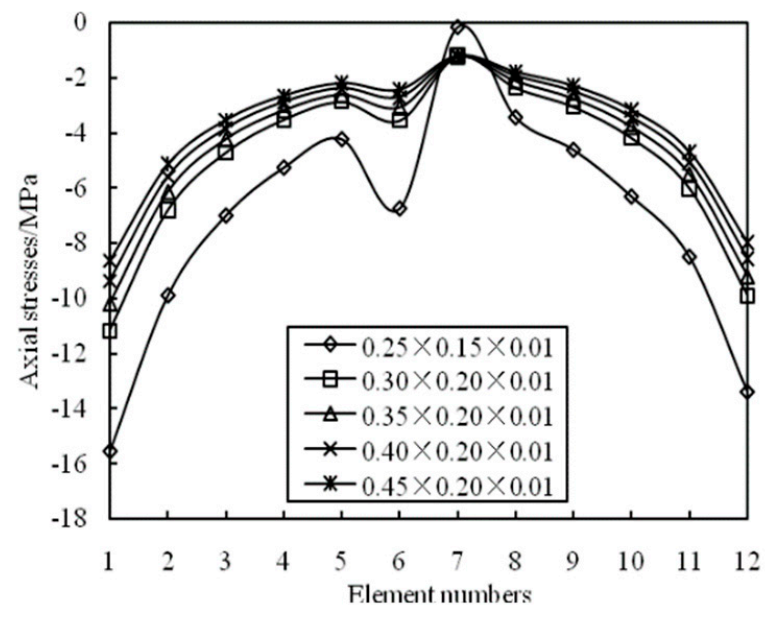

(b) Load 2

Figure 16. Influence of cross-section areas of steel beams on beam stresses.

\subsection{Influence of Cable Area}

The influence of different cable sections on the vertical deflection, and the axial stresses, are investigated. For both hoop and radial cables, diameters of 8, 10, 12, 15, and $20 \mathrm{~mm}$ are adopted. The analysis shows that the nodal vertical displacements (Figure 17) decrease with the increase of the cable areas in both load cases. In case of the induced axial stresses, the change of cable area does not have much impact on the steel beams, as shown in Figure 18.

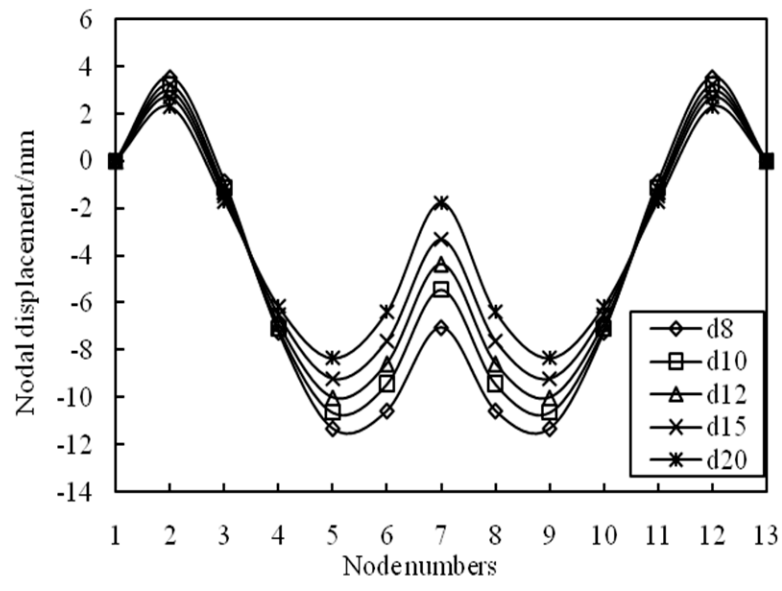

(a) Load 1

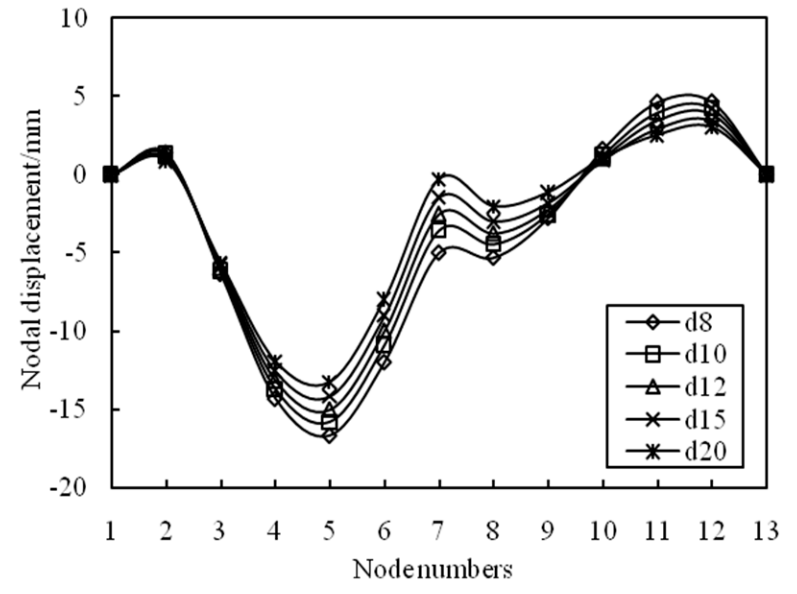

(b) Load 2

Figure 17. Influence of the hoop cable areas on nodal displacements.

For radial cables, the influence of the different cable areas on the vertical displacements of the structure is small (Figure 19). The vertical stiffness of the suspen-dome rises only slightly with the increase of the radial cable area. Figure 20 shows the change of axial stresses in the steel beams of the structure with different radial cable areas. It is evident that the cable area has almost no influence on the axial stresses in steel beams under both Load 1 and Load 2 cases. 


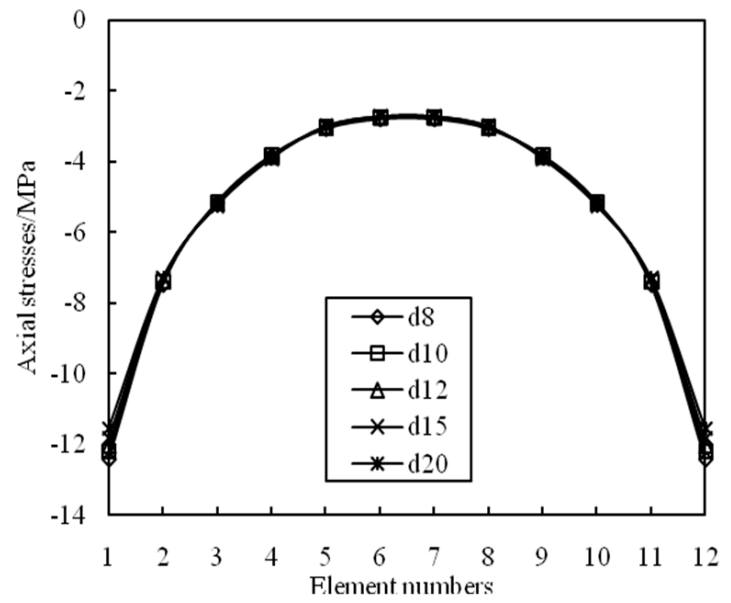

(a) Load 1

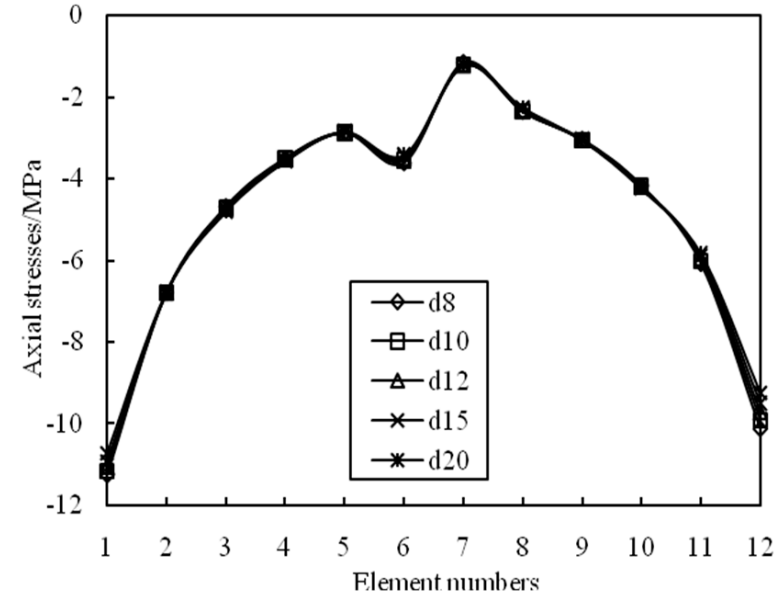

(b) Load 2

Figure 18. Influence of the hoop cable areas on beam stresses.

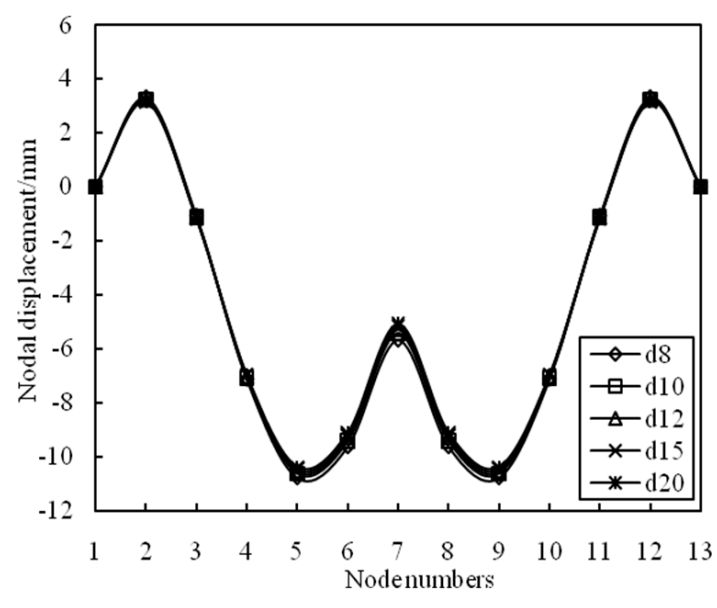

(a) Load 1

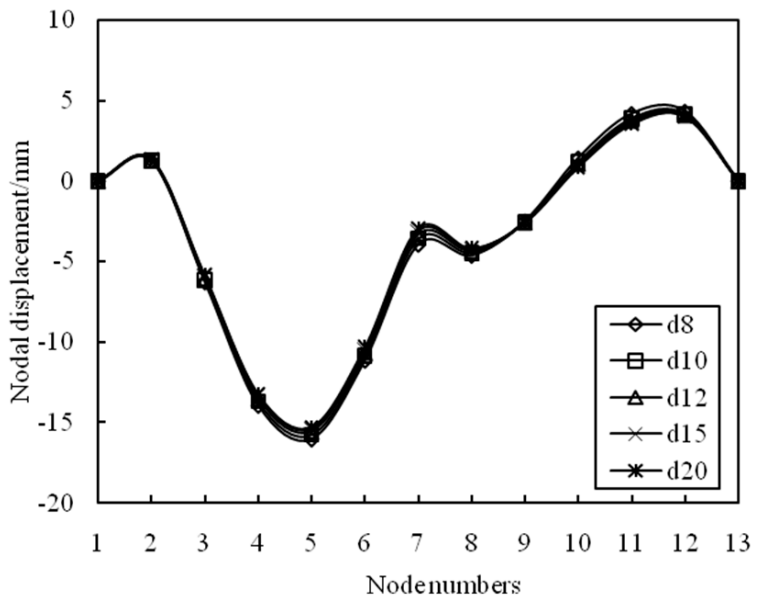

(b) Load 2

Figure 19. Influence of the radial cable areas on nodal displacements.

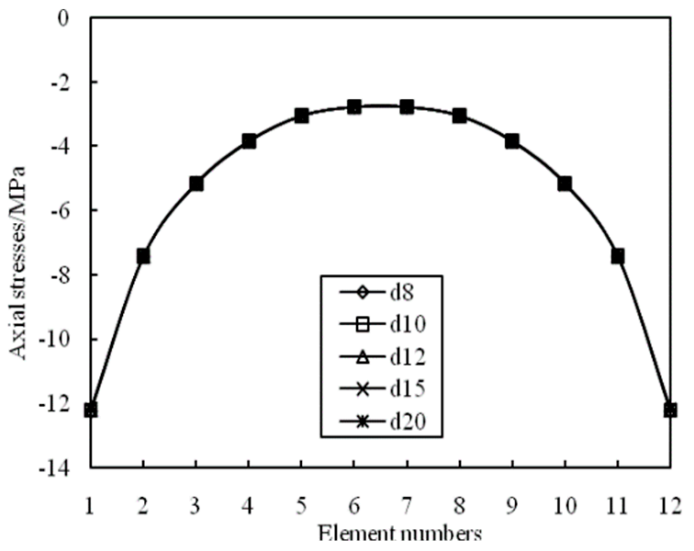

(a) Load 1

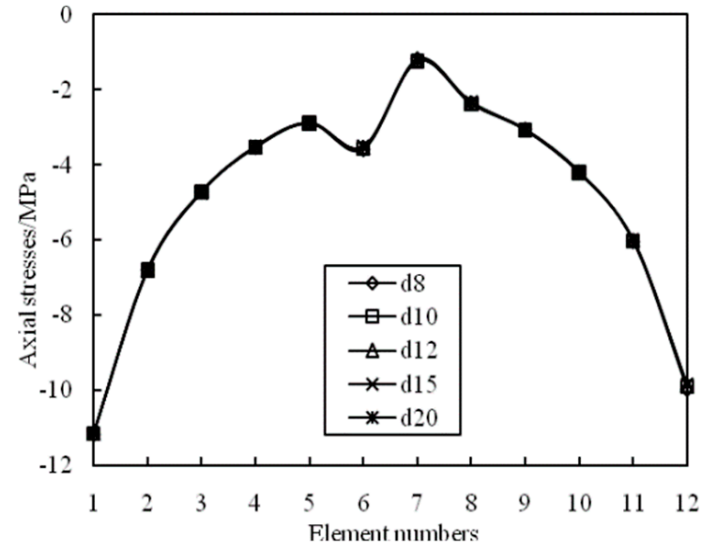

(b) Load 2

Figure 20. Influence of the radial cable areas on beam stresses. 


\subsection{Influence of Cross-Section Area of Struts}

Various strut sections with diameters of 20, 25, 30, 35, and $40 \mathrm{~mm}$ are chosen to study the influence of cross-section area of struts on the static behavior of the retractable suspen-dome. The nodal vertical displacements and axial stresses of the steel beams of the suspen-dome with different cross-section areas of struts are given in Figures 21 and 22. Under both Load 1 and Load 2 cases, the strut section has almost no influence on the nodal displacements and axial beam stresses. Therefore, it will not alter the mechanical behavior of the dome.

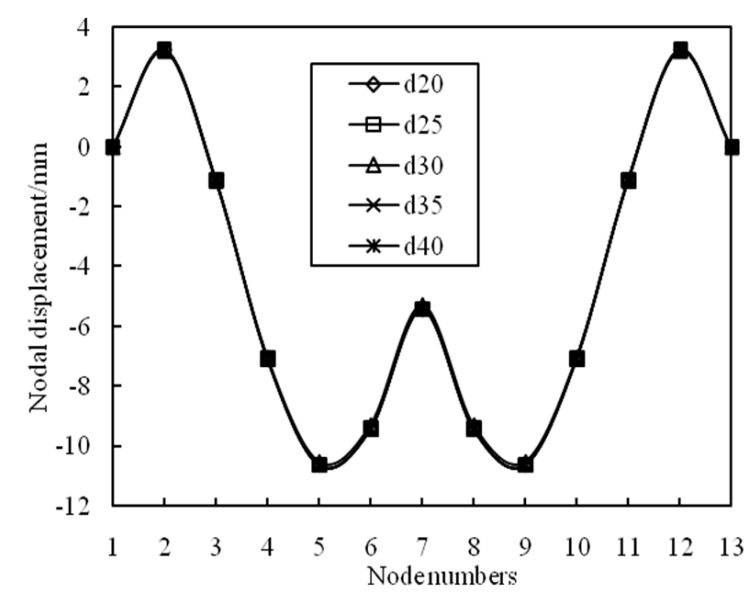

(a) Load 1

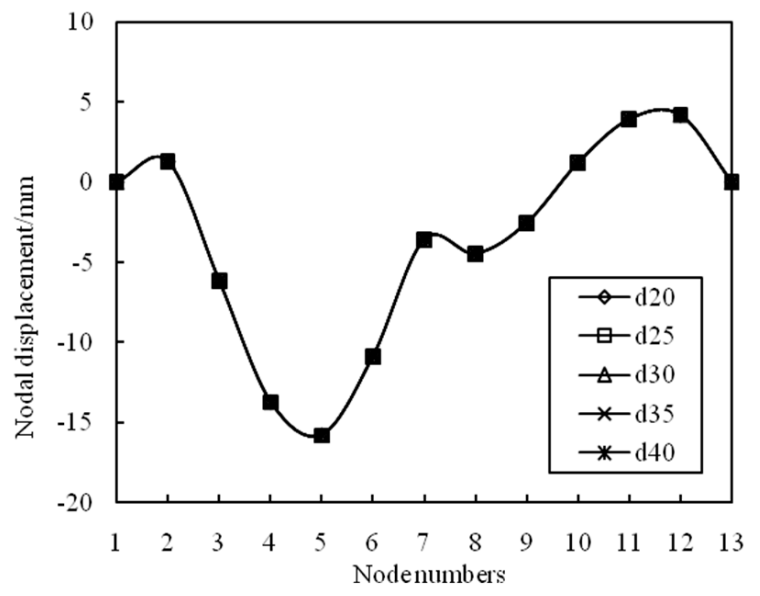

(b) Load 2

Figure 21. Influence of the cross-section area of struts on nodal displacements.

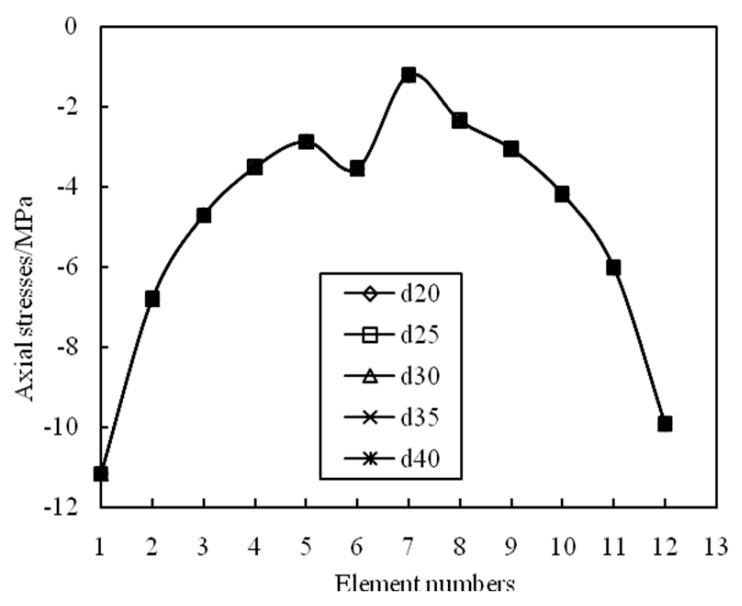

(a) Load 1

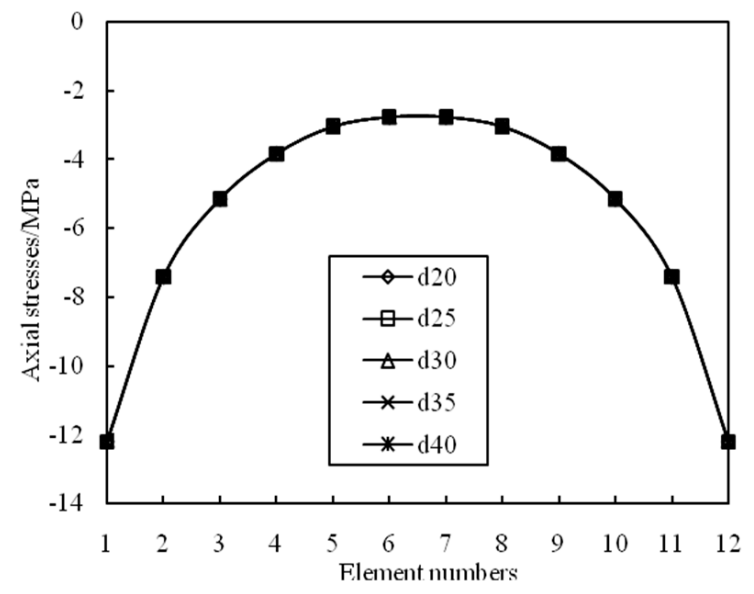

(b) Load 2

Figure 22. Influence of the cross-section area of struts on beam stresses.

\subsection{Influence of Cable Prestress Levels}

As for the final parametric study, the initial prestress levels of the hoop cables in the outset ring are varied at $0,50,100,150$, and $200 \mathrm{MPa}$. The initial prestress of other cables, and struts are obtained by the method given in Section 3.

The results show that the initial prestress level also has an almost negligible influence on the structural behaviors (Figure 23). It is interesting to state that the variations of the initial prestress level in the outset hoop cable (which were ranging from 0 to $200 \mathrm{MPa}$ in the current case) had an insignificant influence on the axial stresses in the steel beams under both load cases (Figure 24). 


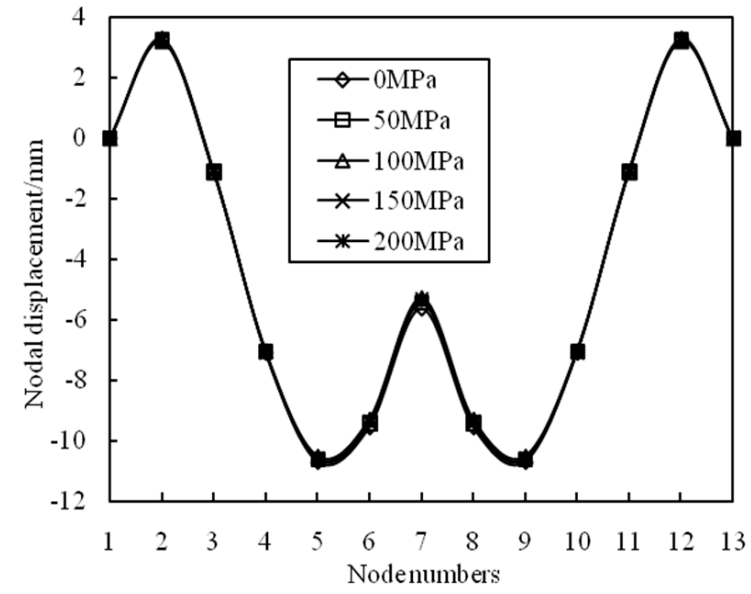

(a) Load 1

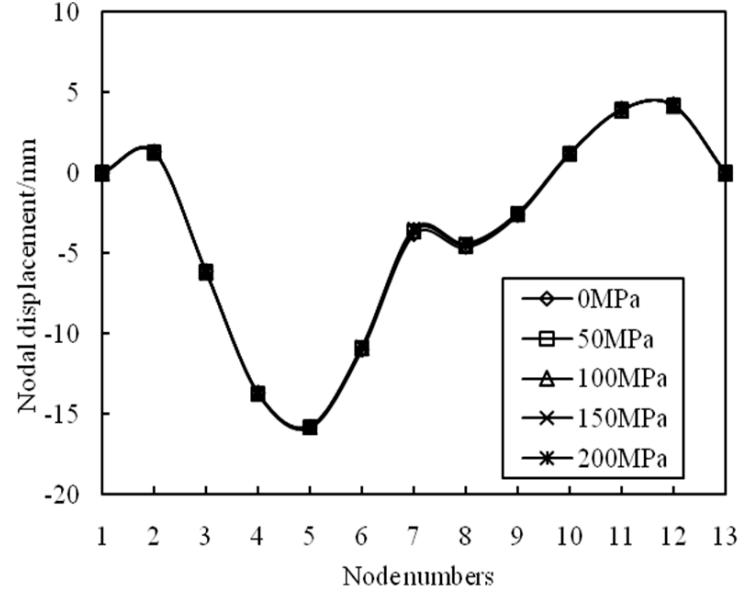

(b) Load 2

Figure 23. Influence of cable prestress levels on nodal displacements.

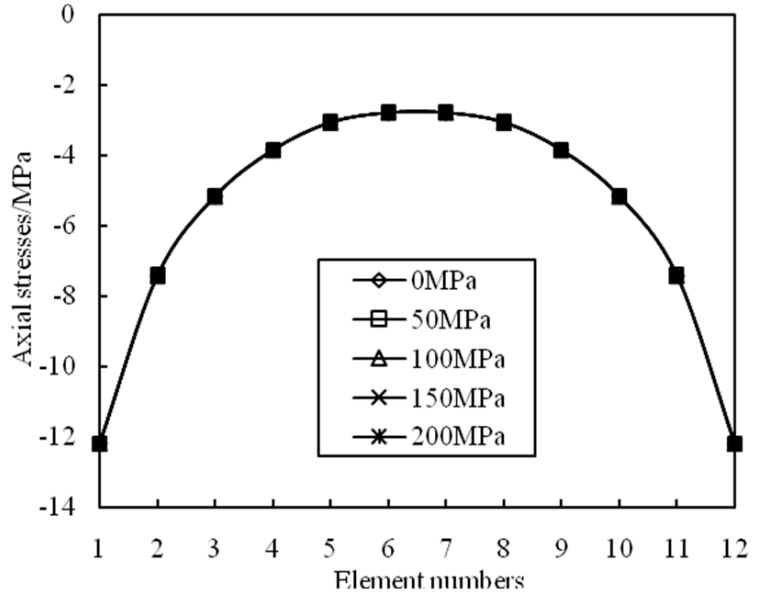

(a) Load 1

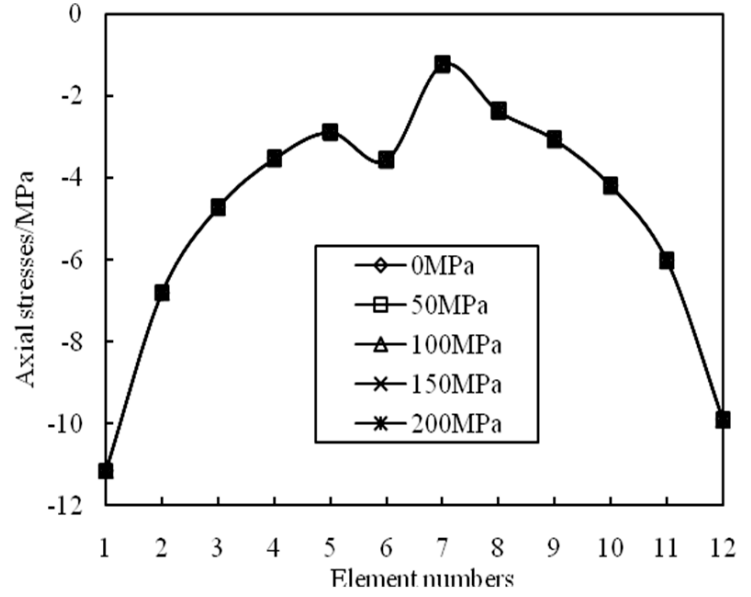

(b) Load 2

Figure 24. Influence of cable prestress levels on beam stresses.

\section{Conclusions}

The conception of a suspen-dome structure was first introduced into a radially retractable roof system to form a radially retractable suspen-dome. Then the static behavior of the system was investigated, followed by a numerical parametric analysis of the retractable suspen-dome in the closed position to obtain better structural performance with higher stiffnesses and lower internal forces for the requirements of loading bearing and moving.

Based on the results, the following conclusions are drawn. The supporting cable-strut system strengthens the retractable roof system. The structure with a cable-strut system has smaller nodal displacements and lower member forces than the foldable bar structure only. The optimal rise-to-span ratio for the retractable suspen-dome is 0.2 , and the other ratios, either larger or less, increased the maximal nodal displacements in the structure. Axial forces in the steel beams decrease as the rise-to-span ratio increases. The increase of the cross-section area of the steel beams contributes significantly to the stiffness of the retractable suspen-dome. In addition, the induced axial stresses in the steel beams decrease accordingly with the increase of the cross-section area. Increasing the cross-section area of the supporting cable-strut system (hoop and radial cable sections, strut sections) contributes little, if not none, to the mechanical behavior of the retractable suspen-dome. Furthermore, 
the initial prestress level in the cable-strut system does not have much influence on the structural behaviour of the retractable suspen-dome.

Author Contributions: Conceptualization, J.C. and J.F.; methodology, X.S.; software, Q.Z.; validation, X.S., Q.Z. and D.S.-H.L.; formal analysis, X.S.; investigation, X.S. and Q.Z.; writing—original draft preparation; visualization, X.S., Q.Z. and D.S.-H.L.; supervision, J.F. All authors have read and agreed to the published version of the manuscript.

Funding: The work presented in this article was supported by the National Natural Science Foundation of China, grant Nos. 51822805, 51878147, and U1937202.

Institutional Review Board Statement: Not applicable.

Informed Consent Statement: Not applicable.

Data Availability Statement: Data is contained within the article.

Conflicts of Interest: The authors declare no conflict of interest.

\section{References}

1. Ramalingam, R.; Jayachandran, S.A. Postbuckling behavior of flexibly connected single layer steel domes. J. Constr. Steel. Res. 2015, 114, 136-145. [CrossRef]

2. Liu, H.B.; Chen, Z.H.; Xu, S.; Bu, Y.D. Structural behavior of aluminum reticulated shell structures considering semi-rigid and skin effect. Struct. Eng. Mech. 2015, 54, 121-133. [CrossRef]

3. Choi, D.I.; Kim, D.J.; Park, K.G. Dynamic response of 100 m, 200 m, 300 m lattice domes with lrb seismic isolator. J. Civ. Eng. Arc. 2019, 13, 523-537.

4. Zabojszcza, P.; Radoń, U. The impact of node location imperfections on the reliability of single-layer steel domes. Appl. Sci. 2019, 9, 2742. [CrossRef]

5. Abedi, K.; Parke, G.A.R. Progressive collapse of single-layer braced domes. Int. J. Space Struct. 1996, 11, 291-306. [CrossRef]

6. Hamid, Y.S. Progressive Collapse of Double Layer Space Trusses. Ph.D. Dissertation, University of Surrey, Guildford, UK, 2015.

7. Li, H.; Taniguchi, Y. Load-carrying capacity of semi-rigid double-layer grid structures with initial crookedness of member. Eng. Struct. 2019, 184, 421-433. [CrossRef]

8. Tatemichi, I.; Hatato, T.; Anma, Y.; Fujiwara, S. Vibration tests on a full-size suspen-dome structure. Int. J. Space Struct. 1997, 12, 217-224. [CrossRef]

9. Kawaguchi, M.; Abe, M.; Tatemichi, I. Design, tests and realization of suspen-dome system. J. Int. Assoc. Shell Spat. Struct. 1999, 40, 179-192.

10. Kitipornchai, S.; Kang, W.; Lam, H.F.; Albermani, F. Factors affecting the design and construction of Lamella suspen-dome systems. J. Constr. Steel. Res. 2005, 61, 764-785. [CrossRef]

11. Kaveh, A.; Rezaei, M.; Shiravand, M.R. Optimal design of nonlinear large-scale suspen-dome using cascade optimization. Int. J. Space Struct. 2018, 33, 3-18. [CrossRef]

12. Chen, Z.H.; Yan, R.Z.; Wang, X.D.; Liu, H.B.; Xiao, X. Experimental researches of a suspen-dome structure with rolling cable-strut joints. Adv. Steel Constr. 2015, 11, 15-38.

13. Guo, J.M.; Yuan, X.F.; Li, Y.Y.; Dong, S.L. A simple approach for force finding analysis of suspended-domes based on the superposition principle. Adv. Struct. Eng. 2014, 17, 1681-1691. [CrossRef]

14. Liu, H.B.; Han, Q.H.; Chen, Z.H.; Wang, X.; Yan, R.Z.; Zhao, B. Precision control method for prestressing construction of suspen-dome structures. Adv. Steel Constr. 2014, 10, 404-425.

15. Meloni, M.; Cai, J.G.; Zhang, Q.; Lee, D.S.H.; Li, M.; Ma, R.J.; Parashkevov, T.E.; Feng, J. Engineering Origami: A comprehensive review of recent applications, design methods, and tools. Adv. Sci. 2021, 2000636. [CrossRef]

16. Zhang, M.; Parke, G.; Tian, S.; Huang, Y.; Zhou, G. Criterion for judging seismic failure of suspen-domes based on strain energy density. Earthq. Struct. 2018, 15, 123-132.

17. Xiang, P.; Wu, M.E.; Zhou, R.Q. Dynamic analysis of deployable structures using independent displacement modes based on Moore-Penrose generalized inverse matrix. Struct. Eng. Mech. 2015, 54, 1153-1174. [CrossRef]

18. Kim, H.S.; Kang, J.W. Vibration control of smart TMD for retractable-roof spatial structure considering closed and open roof condition. Int. J. Steel Struct. 2017, 17, 1537-1548. [CrossRef]

19. Mao, D.; Luo, Y. Analysis and design of a type of retractable roof structure. Adv. Struct. Eng. 2008, 11, 343-354. [CrossRef]

20. Van Mele, T.; de Temmerman, N.; de Laet, L.; Mollaert, M. Scissor-hinged retractable membrane structures. Int. J. Struct. Eng. 2010, 1, 374-396. [CrossRef]

21. De Temmerman, N.; Alegria Mira, L.; Vergauwen, A. Feasibility of the Universal Scissor Component (USC): Building a Full-scale Deployable Dome. J. Int. Assoc. Shell Spat. Struct. 2012, 53, 227-236.

22. Arnouts, L.I.; Massart, T.J.; de Temmerman, N.; Berke, P.Z. Computational Design of Bistable Deployable Scissor Structures: Trends and Challenges. J. Int. Assoc. Shell Spat. Struct. 2019, 60, 19-34. [CrossRef] 
23. Hoberman, C. Radial Expansion Retraction Truss Structure. US Patent 5,024,031, 18 June 1991.

24. Cai, J.G.; Xu, Y.X.; Feng, J. Kinematic analysis of Hoberman's Linkages with the screw theory. Mech. Mach. Theory 2013, 63, 28-34. [CrossRef]

25. Fenci, G.E.; Currie, N.G. Deployable structures classification: A review. Int. J. Space Struct. 2017, 32, 112-130. [CrossRef]

26. You, Z.; Pellegrino, S. Foldable Bar Structures. Int. J. Solids Struct. 1997, 34, 1825-1847. [CrossRef]

27. Teall, M.J. Deployable Roof Structures. Masters Dissertation, University of Cambridge, Cambridge, UK, 1996.

28. Cai, J.G.; Jiang, C.; Deng, X.W.; Feng, J.; Xu, Y.X. Static analysis of a radially retractable hybrid grid shell in the closed position. Steel Compos. Struct. 2015, 18, 1391-1404. [CrossRef]

29. Cai, J.G.; Liu, Y.Q.; Feng, J.; Tu, Y.M. Nonlinear stability analysis of a radially retractable suspen-dome. Adv. Steel Constr. 2017, 13, 117-131.

30. Cai, J.G.; Zhang, Q.; Zhang, Y.Q.; Lee, D.S.H.; Feng, J. Structural evaluation of a foldable cable-strut structure for kinematic roofs. Steel Compos. Struct. 2018, 29, 669-680.

31. Zhang, Q.; Pan, N.; Meloni, M.; Lu, D.; Cai, J.G.; Feng, J. Reliability analysis of radially retractable roofs with revolute joint clearances. Reliab. Eng. Syst. Saf. 2021, 208, 107401. [CrossRef] 